4 Paulson $\mathrm{J} \mathrm{C}$, McClure $\mathrm{W} O$. Inhibition of axoplasmic transport by colchicine, podophyllotoxin, and vinblastine: an effect on microtubules. Ann NY Acad Sci 1975; 253. 517-27.

5 Markand O N, D'Agostino A N. Ultrastructural changes in skeletal muscle induced by colchicine. Arch Neurol 1971; 24: 72-82.

6 Nilsson J, Ksiazek T, Thyberg J. Effects of colchicine on DNA synthesis, endocytosis, and fine structure of cultivated arterial smooth muscle cells. Exp Cell Res 1983; 143: 367-75.

7 Collot M, Louvard D, Singer S J. Lysosomes ar associated with microtubules and not with intermediate filaments in cultured fibroblasts. Proc Natl Acad Sci USA 1984; 81: 788-92.

8 Cockcroft D W, Gault M H. Prediction of creatinine clearance from serum creatinine. Nephron 1976; 16: 31-41.

9 Wallace S L, Singer J Z, Duncan G J, Wigley F M, Kuncl $R$ W. Renal function predicts colchicine toxicity: guidelines for the prophycolchicine toxicity: guidelines for the prophy 1991; 18: 264-9.

10 Besana C, Comi G, Baldini V, Ciboddo G Bianchi R. Colchicine myoneuropathy. Lancel 1987; ii: $1272-3$.

\section{Polyarteritis nodosa and acute interstitial pneumonia}

Sir: Although about eight reports of patients with polyarteritis nodosa associated with interstitial pneumonia have been published, ${ }^{1-7}$ interstitial pneumonia has not been considered to be a complication of polyarteritis nodosa Of the eight cases with this association, only two cases have been recorded in English publications. ${ }^{7}$ Thus we present one case of polyarteritis nodosa associated with acute interstitial pneumonia.

A 71 year old man was admitted to the hospital on 2 October 1990 . He had complained of fatigue, weight loss, fever, and cough for two months before admission. His temperature was $39^{\circ} \mathrm{C}$ and oedema of the legs was noted Abnormal laboratory data included a white blood cell count of $14.5 \times 10^{9} / 1$ (normal range $4-8 \times 10^{9} / 1$ ) with neutrophilia, haemoglobin concentration $103 \mathrm{~g} / \mathrm{l}(140-180 \mathrm{~g} / \mathrm{l})$, erythrocyte sedimentation rate $31 \mathrm{~mm} / \mathrm{h}(1-7 \mathrm{~mm} / \mathrm{h})$, $\mathrm{C}$ reactive protein +5 , and serum complement (CH50) $18.8 \mathrm{U} / \mathrm{ml} \quad(30-40 \mathrm{U} / \mathrm{ml})$. Both rheumatoid factor and antinuclear antibody were positive. Hepatitis B surface antigen and antibodies were negative. Cryoglobulins were negative. A chest radiograph was normal. The patient was clinically diagnosed as possible polyarteritis nodosa and was treated with corticosteroids (prednisolone $60 \mathrm{mg} /$ day) Two months later both rheumatoid factor and antinuclear antibody were negative, and $\mathrm{CH} 50$ had returned to normal.

On 4 January 1991 he complained of dyspnoea. Arterial blood gas analysis at room air showed a partial pressure of oxygen $\left(\mathrm{PaO}_{2}\right)$ of $32 \mathrm{mmHg}$, partial pressure of carbon dioxide $\left(\mathrm{PaCO}_{2}\right) 32.7 \mathrm{mmHg}$, bicarbonate $23.4 \mathrm{mmol} / \mathrm{l}$, and $\mathrm{pH} 7 \cdot 5$. The chest radiograph showed a diffuse reticular pattern in both lungs (fig 1 ) Although he was treated with a large dose of corticosteroids ( $1 \mathrm{~g}$ of prednisolone a day for six days) based on the clinical diagnosis of acute interstitial pneumonia, he died of respiratory failure on 15 January 1991.

Necropsy showed polyarteritis nodosa affecting multiple organs, including the lung oesophagus, stomach, intestine, liver, spleen, kidney, pancreas, and testis. In the lung the bronchial and pulmonary arteries were affected. Most marked were the changes in the stomach. The arteries along the greater and lesser curvatures of the stomach contained numerous nodules, often arranged in chains like a string of pearls. Moreover, many nodules produced protuberances of the gastric mucosa so that the inner surface of the stomach appeared nodular. Histologically, the affected arteries represented the scar stage of necrotising arteritis according to our classification. ${ }^{8}$ Collapse of the alveolar sacs and dilatation of the alveolar ducts could be seen in all lobes of both lungs (fig 2). Hyaline membrane formation, fibroblast proliferation, and chronic inflammatory cell infiltrate were present in the alveolar septae. Moreover, cuboidalisation of the alveolar lining cells and thickened pulmonary arteries were noted. These findings correspond to acute interstitial pneumonia. ${ }^{9}$ There was no correlation between interstitial pneumonia and arteritis.

Although interstitial pneumonia associated with collagen vascular diseases has been described, it was believed that polyarteritis nodosa is not complicated with interstitial pneumonia. Recently, Carratalá and coworkers presented two cases of polyarteritis nodosa associated with interstitial pneumonia, and suggested that reports of new cases were needed to determine whether or not this association is real.

Our case represents classic polyarteritis nodosa, indicated by nodule formation, with histological evidence of arteritis of polyarteritis nodosa type. Nodules were originally described, hence the term polyarteritis nodosa, but these nodules are infrequently seen today, either clinically or pathologically. In the

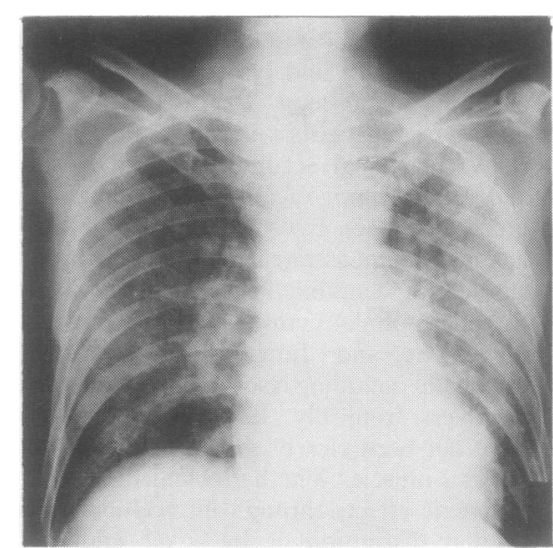

Figure 1 Chest radiograph showing a diffuse reticular pattern in both lungs.

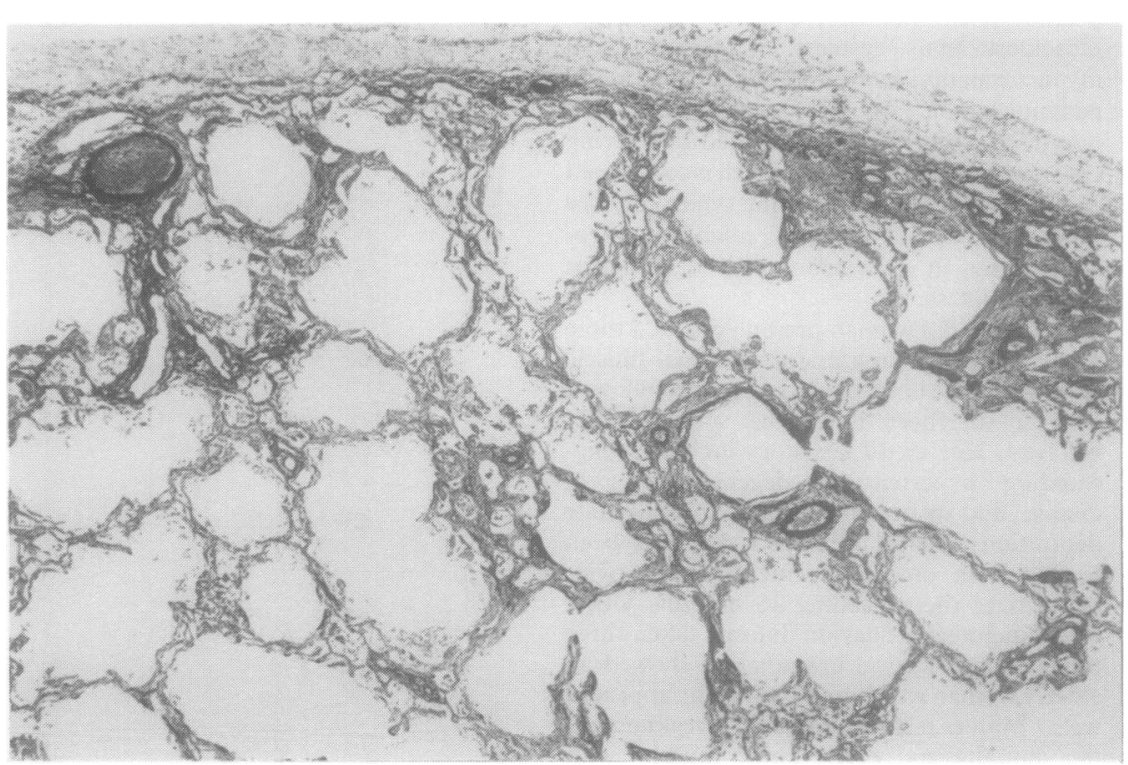

Figure 2 Acute interstitial pneumonia. Note collapse of the alveolar sacs and dilatation of the alveolar

ducts. (Elastic van Gieson stain.)

present case the arteritis represented the scar stage. $^{8}$ On the other hand, the interstitial pneumonia corresponded to the acute stage." Thus we think that interstitial pneumonia overlapped the pre-existing polyarteritis nodosa in this case.

A nationwide research team was organised under the auspices of the Ministry of Health and Welfare of Japan in 1973 to investigate polyarteritis nodosa. The research team analysed 56 patients with polyarteritis nodosa, of whom $10(18 \%)$ clinically had interstitial pneumonia ${ }^{10}$ Moreover, our own experience of three patients with polyarteritis nodosa (the present one and two previously reported ${ }^{5}$ showed that two had interstitial pneumonia These findings indicate that polyarteritis nodosa associated with interstitial pneumonia is apparently more common than has previously been recognised. Thus during treatment of polyarteritis nodosa it may be necessary to treat overlapping interstitial pneumonia.

T MATSUMOTO
M OKADA
N KUWABARA
First Department of Pathology
Juntendo University
School of Medicine
Tokyo, fapan
S HOMMA
T SUZUKI
S KIRA
Department of Respiratory Medicine
Funtendo University
School of Medicine
Tokyo, fapan
T UEKUSA
S SAIKI
St Luke's International Hospital
Tokyo, fapan

Correspondence to: Dr Toshiharu Matsumoto, First Department of Pathology, Juntendo University, Tokyo, 113 Japan.

1 Gherman G, Niculescu I, Serban A L, Caluser I Uber einen Fall von Periarteriitis nodosa mit interstitieller, diffuser Lungenfibrose und parietaler fibröser Endokarditis. Z Gesamte Inn Med 1963; 18: 827-9.

2 Turiaf J, Basset F, Battesti J P. Fibrose interstitielle diffuse de la périartérite noueuse. Société Médicale des Hôspitaux de Paris 1965; 116: 1149-60.

3 De Biasio R, Stanisic M, Reutter F W. Diffuse Lungenfibrose bei Panarteriitis nodosa. Schweiz Med Wochenschr 1973; 103: 1540-3. 
4 Accarino A, Richart C, Lucas A, Pedreira J D, Alomar C. Neumonía intersticial linfoidea y periarteritis nodosa. Rev Clin Esp 1983; 171: periarter.

5 Homma S. A histopathological study on vascular and interstitial changes in the lungs of collagen diseases. Fapanese Fourmal of Thoracic Disease 1985; 23: 332-47.

6 Pankow W, Pohl-Reuling B, Wichert P. Ausgeprägte Lungenbeteiligung bei Periarteriitis nodosa. Med Klin 1988; 83: 231-4.

7 Carratalá J, Vidaller A, Maña J, Manresa F, Fernandez-Nogues F. Polyarteritis nodosa associated with idiopathic pulmonary fibrosis: report of two cases. Ann Rheum Dis 1989; 48: 876-9.

8 Matsumoto T, Yoshimine T, Shimouchi K, et al. The liver in systemic lupus erythematosus: pathological analysis of 52 cases and review of Japanese autopsy registry data. Hum Pathol. In press.

9 Katzenstein A-L A, Askin F B. Surgical pathology of non-neoplastic lung disease. Philadelphia: Saunders, 1990: 35-9.

10 Shiokawa Y. Summarized report of studies. Annual report of malignant rheumatoid arthritis and periarteritis nodosa research committee of fapan. Tokyo: Ministry of Health and Welfare of Japan, 1975: 21-2.

\section{Radiographic assessment of the knee joint in OA}

Sir: The article of Cooper et al, on reproducibility of radiological assessment of the knee joint in osteoarthritis, ' considers a subject integral to the science of rheumatology. The surprisingly poor reproducibility of the cardinal radiological sign of osteoarthritis (osteophytes) $^{2}$ in this Bristol Study contrasts with the observations of Altman's 15 centre study. ${ }^{2}$ Experienced rheumatologists took part in the latter, whereas four of the five observers in the Bristol study were trainees. The poor reproducibility from three of the five observers raises an intriguing possibility. Does the study actually consider the effectiveness and reproducibility of rheumatologists in interpreting radiographs, or solely the efficacy of a particular training programme in teaching the skills in question?

Failure to observe differential reproducibility of joint space assessment between medial and lateral knee compartments was most perplexing. This suggests that the Bristol team observers were no more accurate in assessing the 'normal' compartment of the joint than the 'affected' compartment. Combination of data from 'normal' and osteoarthritic compartments seems even to under- mine the original premise that this was a study of osteoarthritis.

If Samuel Clemens (Mark Twain) is correct that statistics can be considered as one of the various forms of lies, the failure to achieve statistical significance may be misleading. The blinded nature of the analysis may not overcome an apparent fundamental statistical premise violation, related to non-random selection of who reviewed which films. $\beta$ Error (related to limited sample size) and phenomenon infrequency (making use of $\chi^{2}$ inappropriate) further compromise interpretation.

The comments on observations of a difference in order of appearance and of clustering of findings and use of the peculiar ill-defined phrase 'abnormality of bony contour' intriguing possibility, as only osteophytes have actually been demonstrated as a reliable radiological sign of osteoarthritis. ${ }^{2}$ Do the differential appearance order and clustering indicate that perhaps we have been grouping phenomenon with osteoarthritis that are at best tangential? Are we dealing with the traditional overlapping circles of phenomenon which so punctuate the epidemiological chapters in McCarty's text? ${ }^{3}$

BRUCE M ROTHSCHILD The Arthritis Center of Northeast Ohio Northeast Ohio
5701 Market Street 5701 Market Street
Youngstown Ohio 44512, USA

1 Cooper C, Cushnaghan J, Kirwan J R, Dieppe P A, McAlindon T, McCrae F. Radiographic assessment of the knee joint in osteoarthritis. Ann Rheum Dis 1992; 51: 80-2.

2 Altman R, Alarcon G, Appelrouth D, et al. Criteria for classification and reporting of osteoarthritis of the knee. Arthritis Rheum. In press.

3 Masi A T, Medsger T A Jr. Epidemiology of the rheumatic diseases. In: McCarty D J, ed. Arthritis and allied conditions. 11th ed. Philadelphia: Lea and Febiger, 1989: 16-54.

AUTHORS' REPLY: We were interested to read Dr Rothschild's comments on our study of radiological assessment of the knee joint in osteoarthritis. We agree that the reproducibility of these assessments is a subject integral to rheumatological research and practice. Although we cannot be expected to comment on the American College of Rheumatology study which is still in press, we are uncertain that the reproducibility with which osteophytosis was assigned in our study was markedly different from that reported using a similar scale by Altman et al. ${ }^{2}$ The lowest intraclass correlation between observers for spurs in that study was 0.56 , as compared with a $x$ statistic of 0.58 in our study. Indeed, we emphasised in our paper that assessment of joint space narrowing and osteophyte in the tibiofemoral compartment performed rather better than did sclerosis and cyst formation. Dr Rothschild is correct that one of the reasons why reproducibility in our study might have been generally worse than in others relates to the observers chosen for the study. One of our specific aims, however, was to examine the assessment of these features in routine practice rather than to ascertain the optimum performances which could be attained by highly trained observers. Indeed, we highlighted the potential role of training to reduce observer variation as an area for further research.

We were unable to understand Dr Rothschild's statistical comments. If he is lamenting the widespread use of statistical inference in biomedical research, space does not permit us to do more than profoundly disagree with him. The study was designed so that all the observers viewed all the radiographs unaware as to their own or colleagues' previous assessments. The statistical analysis of observer variation is controversial, but we chose to use the $x$ statistic (rather than the $\chi^{2}$ statistic as your correspondent implies). We took pains to emphasise the pitfalls of this analytical technique, but ultimately decided that a summary index of the concordance for various measurements justified its use. It remains one of the most widely used tools to assess the reproducibility of categorical scales. ${ }^{3}$

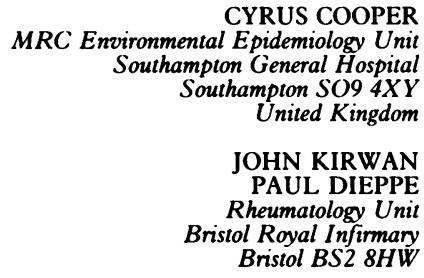

1 Cooper C, Cushnaghan J, Kirwan J R, Dieppe P A, McAlindon T, McCrae F. Radiographic assessment of the knee joint in osteoarthritis. assessment of the knee joint in
Ann Rheum Dis 1992; 51: 80-2.

2 Altman R D, Fries J F, Bloch D A, et al. Radiographic assessment of progression in osteoarthritis. Arthritis Rheum 1987; 30 1214-25.

3 Brennan P, Silman A. Statistical methods for assessing observer variability in clinica assessing observer variability in
measures. BMF 1992; 304: 1491-4. 